\title{
Activation of the Small GTPase Rap1 in Human Neutrophils
}

\author{
By Laura M'Rabet, Paul Coffer, Fried Zwartkruis, Barbara Franke, Anthony W. Segal, \\ Leo Koenderman, and J ohannes L. Bos
}

\begin{abstract}
The small GTPase Rapl is highly expressed in human neutrophils, but its function is largely unknown. Using the Rap1binding domain of RalGDS (RalGDS-RBD) as an activationspecific probe for Rap1, we have investigated the regulation of Rapl activity in primary human neutrophils. We found that a variety of stimuli involved in neutrophil activation, including fMet-Leu-Phe (fMLP), platelet-activating factor (PAF), granulocyte-macrophage colony-stimulating factor (GM-CSF), and IgG-coated particles, induce a rapid and transient Rapl activation. In addition, we found that Rapl is normally activated in neutrophils from chronic granulomatous disease patients that lack cytochrome $b_{558}$ or p47phox
\end{abstract}

$\mathbf{N}$ EUTROPHILS PLAY AN important role in the host defense to microbial pathogens. Stimulation of these cells induces multiple responses, including cell adhesion, migration, secretion, phagocytosis, and the generation of reactive oxygen species. Deregulated activation of neutrophils is implicated in the pathogenesis of a variety of inflammatory diseases leading to tissue damage. Therefore, neutrophil function is under tight control. ${ }^{1-5}$ A diverse array of receptors are expressed on the surface of neutrophils, allowing regulation by a wide range of agonists. Tyrosine kinase-linked receptors (eg, granulocyte-macrophage colony-stimulating factor [GM-CSF] receptors), serpentine receptors (eg, $\mathrm{N}$-formylmethionyl-leucylphenylalanine [fMLP] and platelet-activating factor [PAF] receptors), and receptors that are stimulated by immune complexes such as the Fc receptors, activate distinct and overlapping signaling pathways regulating neutrophil responses ${ }^{6,7}$ (and references therein).

Several small GTPases have been implicated in controlling neutrophil function. In particular, Rac1 was shown to play an important role in the formation of the NADPH oxidase complex, thereby controlling the respiratory burst. $^{2}$ In addition, receptor-dependent activation of Ras was recently demonstrated. ${ }^{6}$ Another small GTPase suggested to play a role in neutrophil function is the Ras-like small GTPase Rap1. Rap1 has an effector domain virtually identical to Ras, and it has been shown that ectopic expression of Rap1, under certain conditions, antagonizes Ras signaling. Of the two known isozymes of Rap1, Rap1A and Rap1B, Rap1A is highly expressed in neutrophils and has been found in a large complex with cytochrome $b_{588} \cdot{ }^{8}$ However, the physiological relevance of this association is still unknown, because Rap1 is not necessary to reconstruct a functional NADPH-oxidase complex in vitro. ${ }^{9}$ However, it has been suggested Rap1 may mediate signaling events controlling the respiratory burst. ${ }^{10,11}$

We have recently developed a novel assay to measure activation of Rap1, ie, the accumulation of Rap1 in its GTP bound form. ${ }^{12}$ This assay is based on the high affinity of the Rap1-binding domain of RalGDS (RalGDS-RBD) for Rap1GTP, but not for Rap1GDP. In platelets, we observed that Rap1 is very rapidly activated by $\alpha$-thrombin and various other platelet agonists. For this rapid activation, elevated levels of intracellular calcium were necessary and sufficient. ${ }^{12}$ To investigate the possible activation and function of Rap1 in human neutrophils, we have analyzed which stimuli might lead to an increase in and have a defective NADPH oxidase system. From these results we conclude that in neutrophils Rapl is activated independently of respiratory burst induction. Finally, we found that Rapl is activated by both the $\mathrm{Ca}^{2+}$ ionophore ionomycin and the phorbol ester 12-0-tetradecanoylphorbol 13-acetate (TPA), indicating that phospholipase C (PLC) activation leading to elevated levels of intracellular free $\mathrm{Ca}^{2+}$ and diacylglycerol (DAG) can mediate Rapl activation. However, inhibition of PLC and $\mathrm{Ca}^{2+}$ depletion only marginally affected $f M L P$-induced Rapl activation, suggesting that additional pathways may control Rapl activation. (C) 1998 by The American Society of Hematology.

GTP-bound Rap1. We found that Rap1 is activated by a variety of stimuli, each with distinct kinetics, including fMLP, PAF, GM-CSF, the phorbol ester 12-O-tetradecanoylphorbol 13acetate (TPA), and IgG-coated particles. Furthermore, we show that multiple signaling pathways direct the activation of Rap1. Finally, this activation is independent of both a functional NADPH oxidase complex and the presence of cytochrome $b_{588}$.

\section{MATERIALS AND METHODS}

Isolation of human neutrophils. Blood was obtained from healthy volunteers from the Red Cross Blood Bank (Utrecht, The Netherlands). Mixed granulocytes were isolated from the buffy-coat of $500 \mathrm{~mL} 0.4 \%$ (wt/vol) tri-sodium citrate $(\mathrm{pH}$ 7.4) -treated blood as previously described. ${ }^{13}$ Mononuclear cells were removed by centrifugation over isotonic Percoll (1.078 g/mL) from Pharmacia (Uppsala, Sweden). After lysis of the erythrocytes in isotonic $\mathrm{NH}_{4} \mathrm{Cl}$ solution, neutrophils were washed and resuspended in incubation buffer $(20 \mathrm{mmol} / \mathrm{L} \mathrm{HEPES}$, $132 \mathrm{mmol} / \mathrm{L} \mathrm{NaCl}, 6 \mathrm{mmol} / \mathrm{L} \mathrm{KCl}, 1 \mathrm{mmol} / \mathrm{L} \mathrm{MgSO}_{4}, 1.2 \mathrm{mmol} / \mathrm{L}$ $\mathrm{KH}_{2} \mathrm{PO}_{4}, 5 \mathrm{mmol} / \mathrm{L}$ glucose, $1 \mathrm{mmol} / \mathrm{L} \mathrm{CaCl}_{2}$ ) containing $0.5 \%$ human serum albumin (HSA; Central Laboratory of The Netherlands Red Cross Blood Transfusion Service, Amsterdam, The Netherlands). Neutrophils were incubated for 30 minutes at $37^{\circ} \mathrm{C}$ before stimulation. Neutrophils isolated in this manner were in the resting state. Neutrophils for the experiments described in Fig 4 were isolated as described. ${ }^{14}$ In all experiments, a concentration of $10^{7}$ cells $/ \mathrm{mL}$ was used for stimulation.

Neutrophil stimulation. One milliliter of neutrophil suspension was stimulated with one of the following stimuli: fMLP ( $1 \mu \mathrm{mol} / \mathrm{L}), \operatorname{PAF}(1$ $\mu \mathrm{mol} / \mathrm{L})$, TPA (100 ng/mL), thapsigargin (100 nmol/L) (all from Sigma, St Louis, MO), GM-CSF (0.1 nmol/L; Genzyme, Boston, MA), and

From the Laboratory for Physiological Chemistry and Department of Pulmonary Diseases, Utrecht University, Utrecht, The Netherlands; and the University of London Hospital, London, UK.

Submitted February 28, 1998; accepted May 14, 1998.

Supported by grants from the Netherlands Heart Association (B.F.), the Dutch Cancer Society (F.Z.), and Glaxo Wellcome (P.C.).

Address reprint requests to Johannes L. Bos, PhD, Laboratory for Physiological Chemistry, Utrecht University, Universiteitsweg 100, 3584 CG Utrecht, The Netherlands; e-mail: j.l.bos@med.ruu.nl.

The publication costs of this article were defrayed in part by page charge payment. This article must therefore be hereby marked "advertisement" in accordance with 18 U.S.C. section 1734 solely to indicate this fact.

(C) 1998 by The American Society of Hematology.

0006-4971/98/9206-0009\$3.00/0 
ionomycin (100 nmol/L; Calbiochem, La Jolla, CA). The concentrations used are known to prime neutrophils or activate the respiratory burst. ${ }^{15-17}$ In some experiments, cells were preincubated as described in the legends of the figures with one of the following inhibitors: IBMX, prostaglandin $\mathrm{E}_{2}\left(\mathrm{PGE}_{2}\right)$, wortmannin, staurosporine (all from Sigma), GF109203X, U73122, or LY294002 (all from Biomol, Plymouth, PA). At different time points, $0.5 \mathrm{~mL} 3 \times \mathrm{RIPA}(1 \times \mathrm{RIPA}: 150 \mathrm{mmol} / \mathrm{L} \mathrm{NaCl}$, $10 \mathrm{mmol} / \mathrm{L}$ Tris- $\mathrm{HCl}$ [pH 7.4], $1 \%$ NP-40, 0.5\% deoxycholic acid, $0.1 \%$ sodium dodecyl sulfate [SDS], $2 \mathrm{mmol} / \mathrm{L}$ phenylmethyl sulfonyl fluoride [PMSF], $2 \mathrm{mmol} / \mathrm{L}$ benzamidine, $4 \mu \mathrm{mol} / \mathrm{L}$ aprotinin, $4 \mu \mathrm{mol} / \mathrm{L}$ leupeptin, and $4 \mu \mathrm{g} / \mathrm{mL}$ trypsin inhibitor) was added.

For stimulation with IgG-coated particles, ${ }^{14} 500 \mu \mathrm{L}$ of $0.8-\mu \mathrm{m}$ latex beads (Difco, Augsburg, Germany) was washed with phosphatebuffered saline (PBS) and suspended in PBS ( $\mathrm{pH} 8.5)$. One hundred microliters of human IgG $(150 \mathrm{mg} / \mathrm{mL}$; Lister Institute, Hertfordshire, UK) was added and incubated for 30 minutes at $37^{\circ} \mathrm{C}$. Beads were washed two times with incubation buffer, resuspended in $500 \mu \mathrm{L}$ incubation buffer, and added to $10^{8}$ cells in $500 \mu \mathrm{L}$ incubation buffer. Samples were stirred continuously and $200-\mu \mathrm{L}$ aliquots were lysed at indicated time points by adding $200 \mu \mathrm{L} 2 \times$ RIPA.

Rap1 activation assay. Rap1 activation was determined essentially as described. ${ }^{12}$ Cell lysates were put on ice for 8 minutes and clarified by centrifugation at $14,000 \mathrm{rpm}$ in an Eppendorf centrifuge for 8 minutes at $4{ }^{\circ} \mathrm{C}$. Per sample, $14 \mu \mathrm{g}$ His-Ral GDS RBD or glutathione S-transferase (GST)-RalGDS-RBD was precoupled for 1 hour to $15 \mu \mathrm{L}$ of 50\% Ni-NTA (nickel-nitrilotriacetic acid agarose; Qiagen, Hilden, Germany) (His-RalGDS-RBD) or $40 \mu \mathrm{L}$ of $10 \%$ glutathione beads (GST-RalGDS-RBD). After coupling, beads were washed 4 times with RIPA, added to the cell lysate, and incubated for 30 minutes at $4^{\circ} \mathrm{C}$. Samples were washed 3 times in RIPA and bound proteins were eluted in $15 \mu \mathrm{L}$ of Laemmli sample buffer. The samples were put on SDS-polyacrylamide gel electrophoresis (SDS-PAGE) and transferred to polyvinylidene difluoride membranes (PVDF; NEN, Boston, MA). Rap1 was detected with a monoclonal antibody (Transduction Laboratories, Lexington, KY) and horseradish peroxidase-coupled goat antimouse (Bio-Rad, Hercules, CA) using enhanced chemiluminescence (Amersham, Buckinghamshire, UK).

Depletion of intracellular free $\mathrm{Ca}^{2+}$. Intracellular free $\mathrm{Ca}^{2+}$ was depleted as described. ${ }^{18}$ Neutrophils were suspended in $\mathrm{Ca}^{2+}$ free incubation buffer supplemented with $1 \mathrm{mmol} / \mathrm{L}$ EGTA. Indo-1/AM (Molecular Probes, Eugene, OR) was added to $1 \mathrm{~mL}$ aliquots of suspended cells $\left(10^{7}\right.$ cells $\left./ \mathrm{mL}\right)$ at a final concentration of $1.5 \mu \mathrm{mol} / \mathrm{L}$. Cells were incubated for 40 minutes at $37^{\circ} \mathrm{C}$. Thapsigargin (100 $\mathrm{nmol} / \mathrm{L}$ ) was added 10 minutes before washing to deplete internal stores. Cells were washed once with $\mathrm{Ca}^{2+}$ free incubation buffer containing EGTA. Determination Rap1 activation and $\mathrm{Ca}^{2+}$ measurements were performed with the same batch of cells. Calcium concentration was measured by a dual excitation at a wavelength of $340 \mathrm{~nm}$ and detected at $390 \mathrm{~nm}$ using Hitachi F4500 fluorescence spectrophotometer (Hitachi Ltd, Tokyo, Japan).

Respiratory burst measurements. Neutrophils were preincubated in the absence or presence of GM-CSF ( $0.1 \mathrm{nmol} / \mathrm{L}$ for 20 minutes $)$. fMLP ( $1 \mu \mathrm{mol} / \mathrm{L}$ ) was added to the cells and oxygen consumption was measured using a Clark oxygen electrode. ${ }^{19}$

\section{RESULTS}

Rapl is activated by a variety of stimuli. Stimulation of human neutrophils with $1 \mathrm{nmol} / \mathrm{L}$ fMLP stimulation results in cell adhesion and chemotaxis. Antipathogenic responses such as degranulation and the generation of oxygen radicals occur only after stimulation with more than $1 \mu \mathrm{mol} / \mathrm{L}$ fMLP and require preactivation with agents such as PAF or GM-CSF. The biochemical mechanism of this preactivation or priming is not fully understood. Furthermore, the priming agents PAF and
GM-CSF differ in that GM-CSF stimulation results only in chemokinesis (undirectional cell motility), whereas PAF stimulation, similarly to fMLP stimulation results in chemotaxis (directional cell movement) 1,2,6,15-17,20 (and references therein).

To investigate whether fMLP, PAF, or GM-CSF can activate Rap1, we stimulated resting neutrophils isolated from human peripheral blood with different ligands for various periods of time. Rap1 was isolated with the 97 amino acid RalGDS-RBD, which specifically binds the active, GTP-bound form of Rap1, followed by detection with Western blotting. ${ }^{12}$ Stimulation with $1 \mu \mathrm{mol} / \mathrm{L}$ fMLP-induced a rapid increase in Rap1 activity with biphasic kinetics (Fig 1). An initial activation peak was observed by 10 seconds, which decreased around 30 seconds. Activity peaked again at 5 minutes, followed by a slow decline toward basal levels observed in resting neutrophils. The extent of activation varied somewhat between different donors (compare Figs 1, 3, and 4B for variation in Rap1 activation after fMLP-stimulation), but the kinetics of Rap1 activation remained essentially constant in all experiments. Approximately $1 \%$ of Rap 1 present in the total lysate of stimulated cells was found to be bound to RalGDS-RBD (Fig 1). This was concluded after comparing the amount of Rap1 present in total lysate and that of Rap1 in the GTP bound state on Western blot. Stimulation with $1 \mu \mathrm{mol} / \mathrm{L}$ PAF also resulted in a rapid activation of Rap1, which peaked around 10 seconds, followed by a slow decline towards basal level. In contrast to fMLP, no second activation peak was observed.

fMLP and PAF both act via serpentine receptors. To investi-

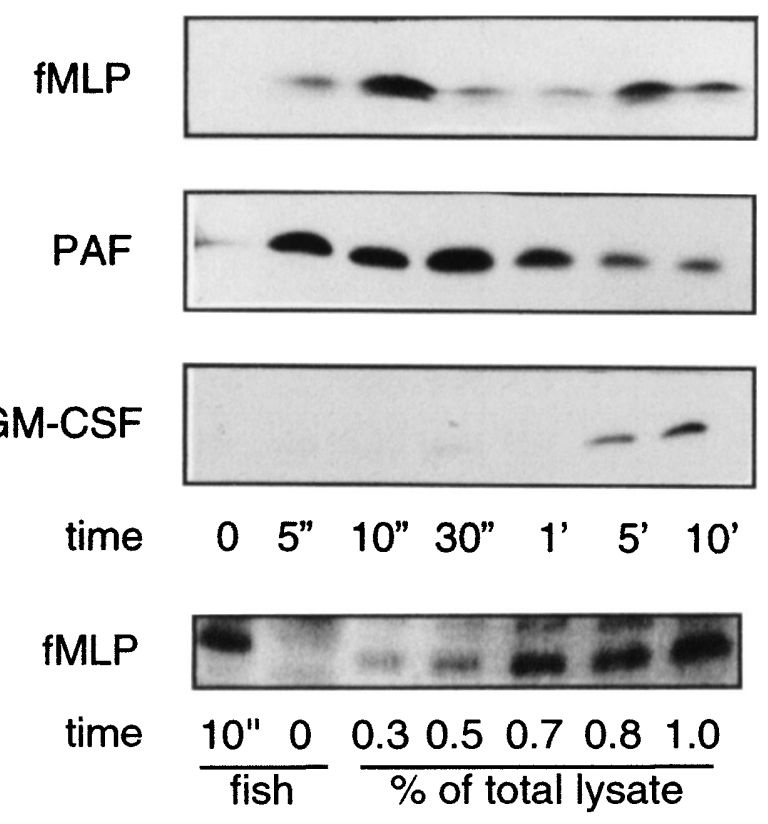

Fig 1. Rapl activation in neutrophils. Neutrophils were stimulated with either $1 \mu \mathrm{mol} / L$ fMLP, $1 \mu \mathrm{mol} / L$ PAF, or $0.1 \mathrm{nmol} / \mathrm{L}$ GM-CSF for indicated time points. Cells were lysed and Rap1 GTP was isolated using His-Ral-GDS RBD. Rap1 was detected by Westem blot analysis using a monoclonal antibody against Rapl. The amount of Rap1 GTP isolated after 10 seconds of fMLP stimulation and unstimulated neutrophils was compared with the amount of total Rapl (Rap1GDP and GTP) present in various amounts (\%) of total lysate. The experiments were repeated at least three times with similar results. 
gate whether Rap1 could be activated via receptor-associated tyrosine kinases, we stimulated neutrophils with GM-CSF $(0.1$ $\mathrm{nmol} / \mathrm{L}$ ). This stimulation resulted in a delayed and weaker activation of Rap1, compared with fMLP- or PAF-induced Rap1 activation, reaching its maximum around 5 to 10 minutes.

Various studies have implicated Rap1 functioning in the production of oxygen radicals. Therefore, we analyzed Rap1 activation by stimuli known to induce a respiratory burst in resting neutrophils. ${ }^{14}$ Incubation with IgG-coated particles resulted in a slow but steady increase of Rap1 activation detectable after 30 seconds, which reached its maximal activity after 4 minutes (Fig 2). A slow increase of Rap1 activation was also observed after treating resting neutrophils with TPA (100 $\mathrm{ng} / \mathrm{mL})$. In this case, Rap1 activation was detectable after 1 minute and reached a maximum after 5 minutes of TPA treatment.

Activation of primed neutrophils by fMLP also induces the respiratory burst (Fig 3A). To investigate whether Rap1 activation is modified under these conditions, we primed neutrophils with $0.1 \mathrm{nmol} / \mathrm{L}$ GM-CSF followed by stimulation with 1 $\mu \mathrm{mol} / \mathrm{L}$ fMLP. As shown in Fig 3B, fMLP induced Rap1 activation to a similar extent both in resting and in primed neutrophils. In general, the kinetics of activation were slightly

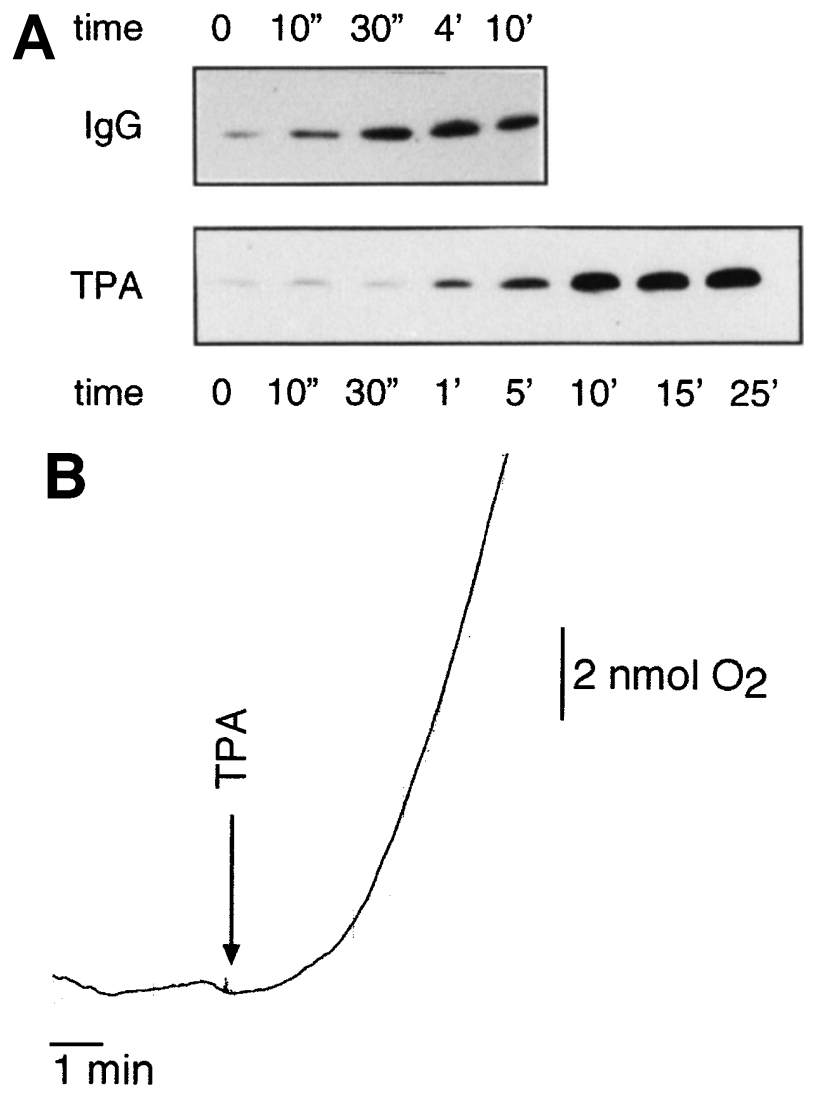

Fig 2. Rapl activation by stimulators of the respiratory burst in resting neutrophils. (A) Neutrophils were stimulated with $100 \mathrm{ng} / \mathrm{mL}$ TPA or IgG-coated latex beads. Samples were taken at indicated time points after stimulation. Rapl activity was determined as described in the legend to Fig 1 . (B) Respiratory burst induced in resting neutrophils by TPA (100 $\mathrm{ng} / \mathrm{mL}$ ) measured using a Clark oxygen electrode.
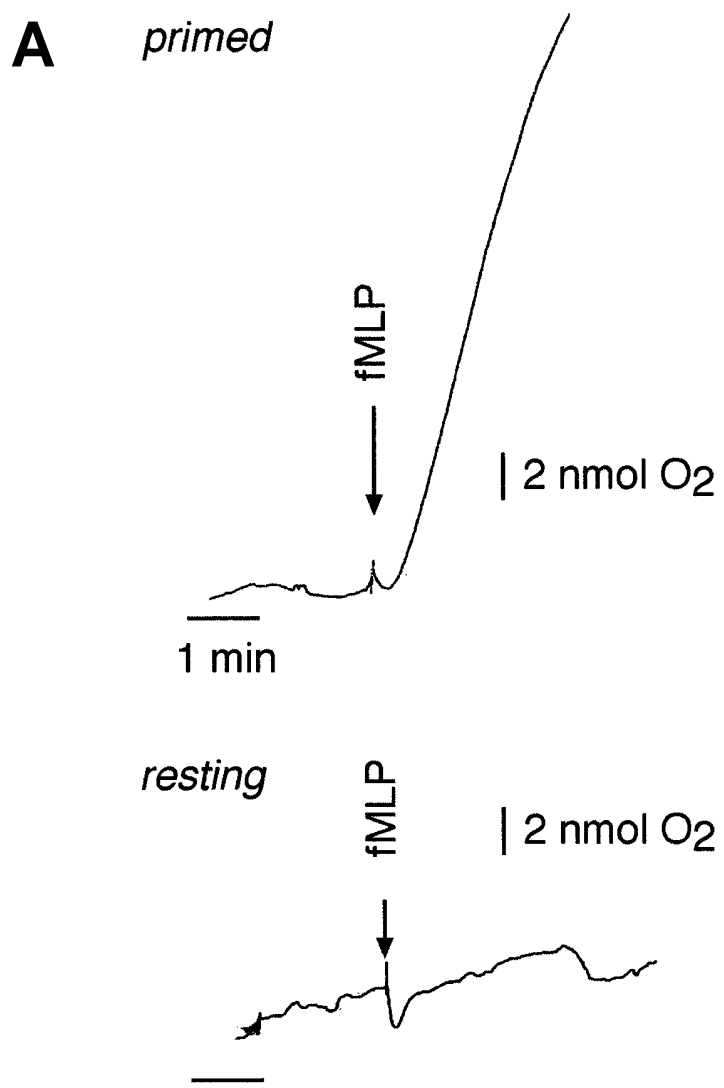

$1 \min$

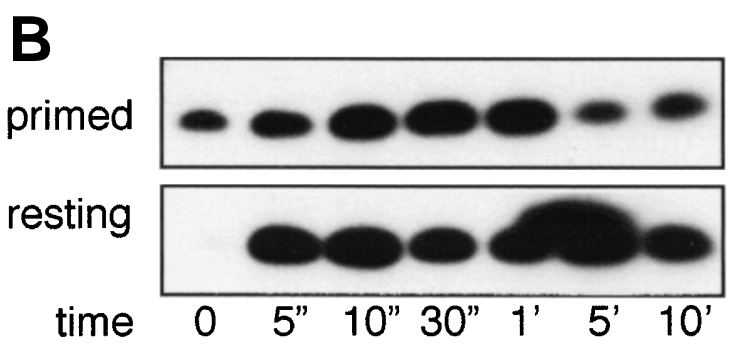

Fig 3. Rap1 activation in resting and primed neutrophils. Rap1 activity is measured in primed and resting neutrophils. Neutrophils were primed by 20 minutes of $0.1 \mathrm{nmol} / \mathrm{L}$ GM-CSF stimulation. Subsequently, resting and primed neutrophils were stimulated with 1 $\mu \mathrm{mol} / \mathrm{L}$ fMLP for the indicated time points. (A) Oxygen consumption was measured with a Clark oxygen electrode. (B) Rapl activation was measured in neutrophils from the same donor as (A). Representative examples of at least three independent experiments are shown.

different, with the first activation peak delayed and the absence of a second peak in the case of primed cells. As a consequence, usually only a single activation peak was observed around 30 seconds, which decreased after 1 minute. Similar results were obtained after priming neutrophils with PAF (data not shown).

Multiple signaling pathways direct fMLP-induced Rap1 activation. Although Rap1 was activated by all agents used, the kinetics of Rap1 activation differed, suggesting that multiple signaling pathways might regulate Rap1 activation. To determine the mechanisms by which Rap1 GTPase is regulated, we investigated fMLP-induced Rap1 activation, because some of 
the signaling pathways used by fMLP in resting neutrophils are defined. fMLP activates a serpentine receptor that is coupled to various heterotrimeric G-proteins (Bokoch $^{7}$ and references therein). After stimulation, phospholipase $C \beta$ (PLC $\beta)$ is activated, resulting in diacylglycerol (DAG)-mediated activation of protein kinase $\mathrm{C}$ (PKC) and inositol 345 triphosphate $\left(\mathrm{IP}_{3}\right)$-mediated $\mathrm{Ca}^{2+}$ mobilization. ${ }^{7,21}$ In addition, phosphatidylinositol-3-kinase (PI-3K) is activated, which may be responsible for the activation of protein kinase $\mathrm{B}(\mathrm{PKB})$ and of Rac GTPases. $^{21-23}$

A possible signaling pathway which may mediate Rap1 activation involves changes in intracellular free $\mathrm{Ca}^{2+}$ concentration $\left(\left[\mathrm{Ca}^{2+}\right]_{i}\right)$. We first investigated whether $\mathrm{Ca}^{2+}$ was able to induce Rap 1 activation, because in human platelets $\alpha$-thrombin induced Rap1 activation is $\mathrm{Ca}^{2+}$-dependent. ${ }^{12}$ Resting neutrophils were incubated with ionomycin and thapsigargin to mimic $\mathrm{Ca}^{2+}$ influx and $\mathrm{Ca}^{2+}$ release from internal stores. As shown in Fig 4A, ionomycin induced a rapid activation of Rap1 to a level similar to fMLP, whereas induction of Rap1 by thapsigargin, although detectable, was clearly lower than that induced by fMLP. Because these experiments indicated that $\mathrm{Ca}^{2+}$ influx may be sufficient to induce Rap1 activation in neutrophils, we next investigated whether an increase in $\left[\mathrm{Ca}^{2+}\right]_{i}$ was essential for Rap1 activation. We therefore depleted neutrophils of $\mathrm{Ca}^{2+}$ by pretreatment with $1 \mathrm{mmol} / \mathrm{L}$ EGTA, $1.5 \mu \mathrm{mol} / \mathrm{L}$ indo-1/AM, or $100 \mathrm{nmol} / \mathrm{L}$ thapsigargin. Under these conditions, $\left[\mathrm{Ca}^{2+}\right]_{i}$ decreased to less than $10 \mathrm{nmol} / \mathrm{L}$ and no increase in $\left[\mathrm{Ca}^{2+}\right]_{i}$ levels was observed after fMLP stimulation (Fig 4B). $\mathrm{Ca}^{2+}$ depletion did not affect the rapid fMLP-induced Rap1 activation, but we did observe a reduction in Rap1 activation at the second activation peak as compared with the control fMLP treatment. Similar results were obtained after inhibition of $\mathrm{Ca}^{2+}$ influx by blocking $\mathrm{Ca}^{2+}$ channels with $\mathrm{La}^{3+}$ (data not shown). From these results we concluded that elevated $\left[\mathrm{Ca}^{2+}\right]_{i}$ is sufficient but not essential to induce Rap1 activation in human neutrophils.

A role for PKC in Rap1 activation was suggested, because TPA induced Rap1 activation in neutrophils (see Fig 2). Therefore, we examined whether inhibitors of PKC could abolish fMLP-induced Rap1 activation. However, the broadspecificity PKC inhibitors staurosporine and GF109203X (bisindolylmaleimide) did not inhibit fMLP-induced Rap1 activa-

A

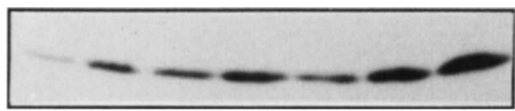

ionomycin

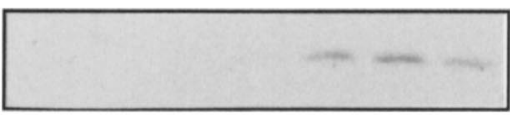

thapsigargin
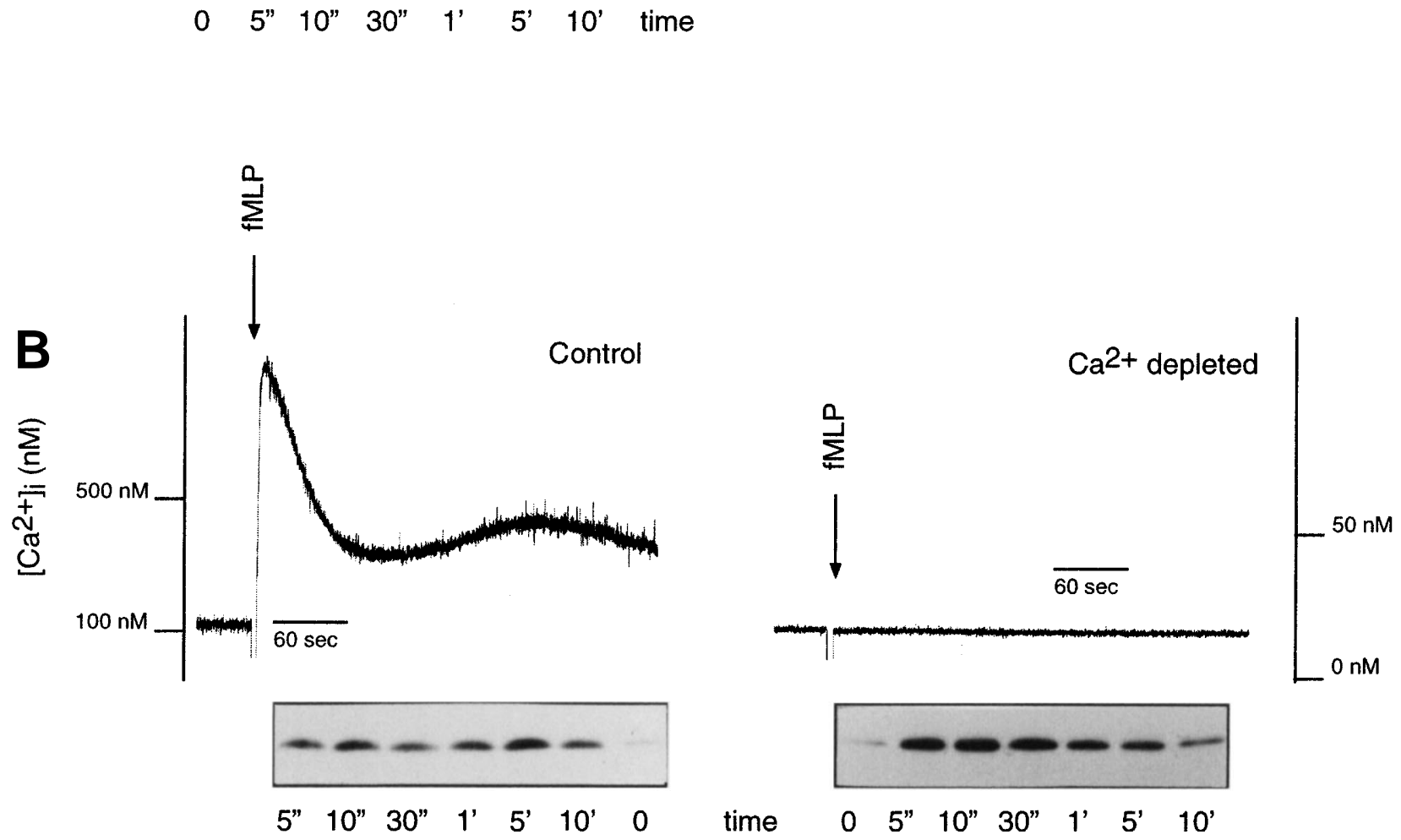

Fig 4. $\mathrm{Ca}^{2+}$ dependency of Rapl activation. (A) Neutrophils were incubated with ionomycin (100 nmol/L) or thapsigargin (100 $\left.\mathrm{nmol} / \mathrm{L}\right)$ for the indicated time points. Rap1 GTP was detected as in the legend to Fig 1 . (B) $\mathrm{Ca}^{2+}$-depleted neutrophils were stimulated with $1 \mu \mathrm{mol} / \mathrm{L}$ fMLP. As a control, non- $\mathrm{Ca}^{2+}$-depleted cells were stimulated with $1 \mu \mathrm{mol} / \mathrm{L} \mathrm{fMLP.} \mathrm{Ca}^{2+}$-depleted and untreated neutrophils of the same donor were taken to measure $\left[\mathrm{Ca}^{2+}\right]_{i}$ after $1 \mu \mathrm{mol} / \mathrm{L}$ fMLP stimulation. Representative examples of at least three independent experiments are shown. 
tion, indicating that the fMLP-induced Rap1 activation is independent of PKC (Fig 5A). Furthermore, most of the TPA-induced Rap1 activation was insensitive to staurosporine, whereas, at the concentrations used, staurosporine effectively abolished TPA-induced respiratory burst (Fig 5B). Thus, Rap1 can be activated directly by TPA and does not require PKC.

Because both elevated levels of $\left[\mathrm{Ca}^{2+}\right]_{\mathrm{i}}$ and TPA-treatment (which mimics the formation of DAG) activated Rap1, PLC $\beta$ may mediate fMLP-induced Rap1 activation. We investigated whether the PLC $\beta$-inhibitor U73122 ${ }^{24}$ could inhibit fMLPinduced Rap1. However, no inhibition of fMLP-induced Rap1 activation was observed (Fig 5C). From these results we concluded that another, distinct signaling pathway regulating Rap1 activation is activated by fMLP or that a U73122insensitive PLC isoform is responsible for the fMLP-induced Rap1 activation. As expected, both inhibition of PKC and $\mathrm{Ca}^{2+}$ depletion did not abolish fMLP-induced Rap1 activation either (Fig 5C).

To investigate whether Rap1 activation is mediated by PI-3K, ${ }^{6}$ we treated resting neutrophils with the PI-3K inhibitors wortmannin and LY294002. Both inhibitors failed to inhibit
fMLP-induced Rap1 activation under conditions that did abolish respiratory burst (Fig 5D and data not shown).

Rapl activation is not inhibited by $P G E_{2}$ and is independent of oxidase assembly and function. In platelets, Rap1 activation by $\alpha$-thrombin is completely inhibited by prostacylin, a platelet antagonist that elevates the levels of cAMP. $\mathrm{PGE}_{2}$ is an antagonist of neutrophils and also elevates the levels of cAMP. In addition, $\mathrm{PGE}_{2}$ was reported to induce Rap1 phosphorylation via cAMP-dependent protein kinase A (PKA), resulting in the dissociation of Rap1 from cytochrome $b_{558}$ in vitro. ${ }^{25}$ We therefore examined if $\mathrm{PGE}_{2}$ could antagonize fMLP-dependent Rap1 activation in neutrophils. However, cotreatment of neutrophils with $\mathrm{PGE}_{2}$ and the phosphodiesterase inhibitor IBMX (which further elevates cAMP levels) did not affect fMLPinduced Rap1 activation (Fig 6). The observation that a similar treatment did inhibit fMLP-induced respiratory burst in GMCSF-primed neutrophils indicated that cAMP does not interfere with the activation of Rap1 GTPase.

That Rap1 activation was not dependent on Rap1 association with cytochrome $b_{558}$ or the formation of the oxidase complex was further confirmed by analysis of Rap1 activation in patients
A

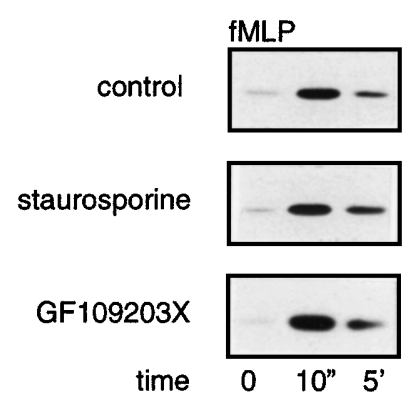

C

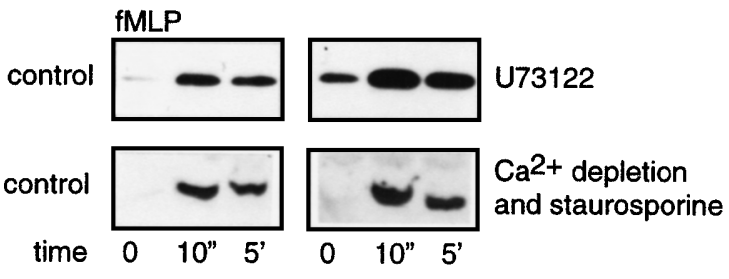

D

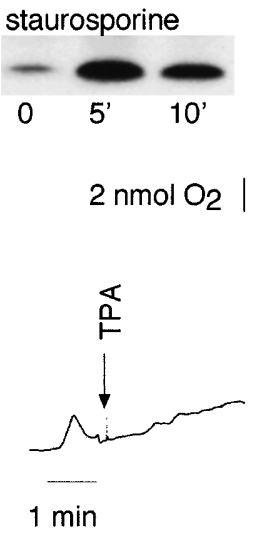

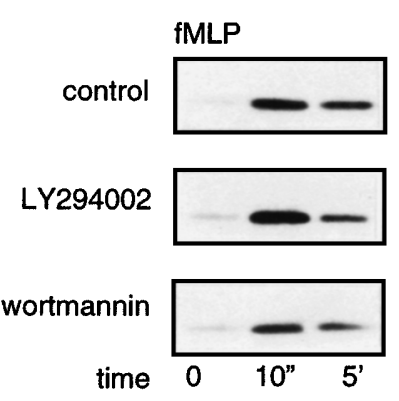

$1 \mathrm{~min}$
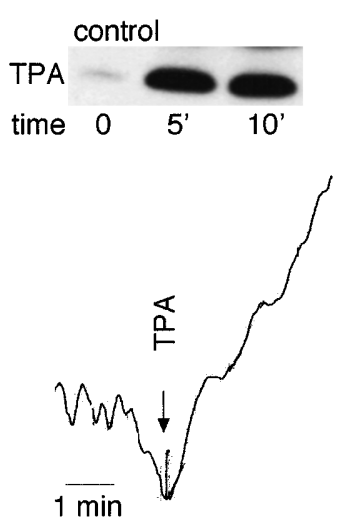

Fig 5. fMLP- and TPA-induced Rapl activation is independent of PKC. (A) fMLP-induced Rapl activation is not inhibited by PKC inhibitors. Neutrophils were preincubated for 5 minutes with $200 \mathrm{nmol} / \mathrm{L}$ staurosporine or 10 minutes with $5 \mu \mathrm{mol} / \mathrm{L}$ GF109203X. Neutrophils were then stimulated with $1 \mu \mathrm{mol} / \mathrm{L} \mathrm{fMLP}$ for 10 seconds and 5 minutes. As a control, untreated neutrophils of the same donor were used. (B) TPA-induced Rapl activity is not inhibited by a PKC inhibitor. Neutrophils were stimulated with $100 \mathrm{ng} / \mathrm{mL}$ TPA for 5 and 10 minutes after preincubation for 5 minutes with $200 \mathrm{nmol} / \mathrm{L}$ staurosporine or buffer. Oxygen consumption was measured with a Clark oxygen electrode to measure the functionality of staurosporine treatment. Representative examples of at least three independent experiments are shown. (C) Inhibition of PLC $\beta$ does not influence Rapl activity. Neutrophils were preincubated with $1 \mu \mathrm{mol} / \mathrm{L}$ U73122 (PLC $\beta$ inhibitor) for 3 minutes and subsequently stimulated with $1 \mu \mathrm{mol} / \mathrm{L}$ fMLP. (D) Rapl activity is not inhibited by PI-3 kinase inhibitors. Neutrophils were preincubated with the Pl-3 kinase inhibitors LY294002 (10 $\mu \mathrm{mol} / \mathrm{L})$ or wortmannin $(100 \mathrm{nmol} / \mathrm{L})$ for 5 minutes. Samples were taken after preincubation and 10 seconds and 5 minutes after $1 \mu \mathrm{mol} / \mathrm{L}$ fMLP stimulation. As a control, neutrophils of the same donor without preincubation were used. Representative examples of at least three independent experiments are shown. 


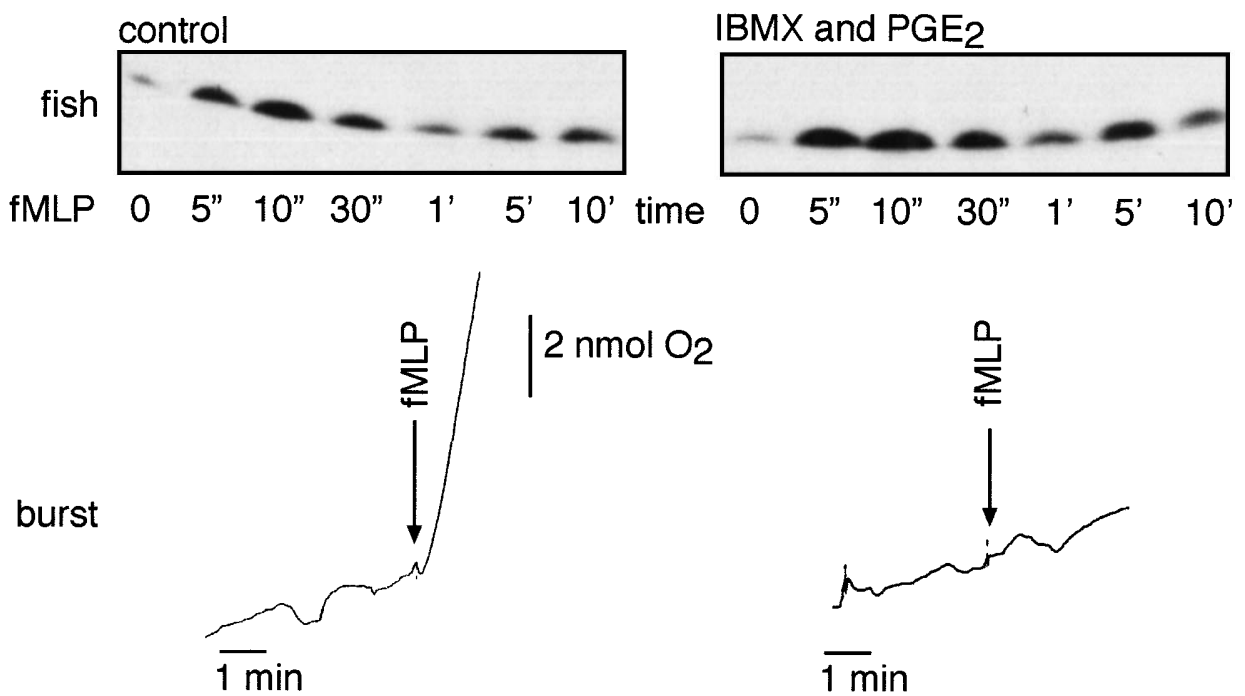

Fig 6. Rapl activation is not inhibited by $\mathrm{PGE}_{2}$ treatments. Neutrophils of a healthy donor were preincubated for $10 \mathrm{~min}$ utes with $100 \mu \mathrm{mol} / \mathrm{L}$ IBMX followed by $\mathbf{3 0}$ seconds of incubation with $30 \mu \mathrm{mol} / \mathrm{L} \mathrm{PGE}_{2}$. Cells were stimulated with $1 \mu \mathrm{mol} / \mathrm{L}$ fMLP, and Rapl activity was measured after the indicated time points. As acontrol, untreated neur trophils were stimulated with the same amount of fMLP. Respiratory burst was measured to control for the functionality of the cAMP treatment. Representative examples of at least three independent experiments are shown. with chronic granulomatous disease (CGD), which lack a functional oxidase complex. ${ }^{26}$ As shown in Fig 7, Rap1 is still activated by both fMLP and TPA in neutrophils isolated from CGD patients, lacking either cytochrome $b_{588}$ (p91phox) or p47phox.

\section{DISCUSSION}

In this report we have investigated the signaling events in human neutrophils that resulted in the activation of Rap1, ie, an increase in levels of Rap1GTP. We have used an assay that uses the Rap1 binding domain of a putative Rap1 effector (RalGDSRBD) to specifically precipitate Rap1GTP. We observed that a variety of stimuli can induce Rap1 activation, but the extent and kinetics of activation varied. A very rapid activation of Rap1 was observed after fMLP and PAF stimulation, whereas slower activation was observed after stimulation with TPA, incubation with IgG-coated particles, or GM-CSF.

Our finding that several stimuli can activate Rap1 may indicate that multiple pathways are involved in the activation of Rap1. Thus far, a study of the activation of Rap1 has only been performed in human platelets and T lymphocytes. In these cells,

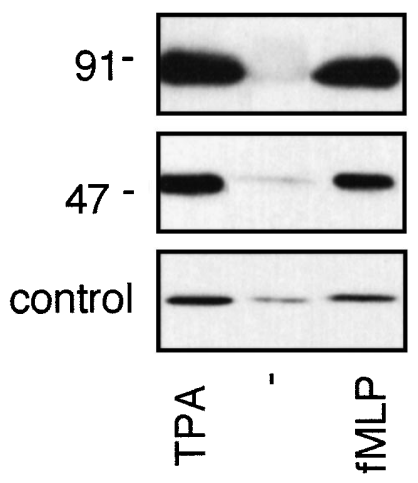

Fig 7. Rapl activation is independent of the presence of a functional NADPH oxidase complex. (A) Neutrophils of a p91phoxdeficient or a p47-deficient patient were stimulated for 5 minutes with $100 \mathrm{ng} / \mathrm{mL}$ TPA or $1 \mu \mathrm{mol} / \mathrm{L}$ fMLP. Rap1 GTP was isolated using GST-Ral-GDS RBD as described in the legend to Fig 1.
Rap1 activation after $\alpha$-thrombin stimulation is mediated by elevated $\left[\mathrm{Ca}^{2+}\right]_{i}$, which is necessary and sufficient. ${ }^{12,27}$ In neutrophils, it appears that, in addition to elevated $\left[\mathrm{Ca}^{2+}\right]_{i}$, other pathways lead to Rap1 activation. Indeed, both ionomycin and, to a lesser extent, thapsigargin induce Rap1 activation, but $\mathrm{Ca}^{2+}$ depletion did not abolish fMLP-induced Rap1 activation as well.

Because TPA efficiently induced Rap1 activation, DAG is a strong candidate to mediate Rap1 activation. PKC, a wellknown target for DAG, is not involved in Rap1 activation, because both the fMLP-induced Rap1 activation and the TPA-induced Rap1 activation were not abolished after treatment with the broad PKC inhibitor staurosporine. This implies that a different DAG target is involved in the regulation of Rap1.

Suprisingly, affecting the elevation of $\left[\mathrm{Ca}^{2+}\right]_{\mathrm{i}}$ and DAG formation by inhibition of PLC $\beta$ did not abolish fMLP-induced Rap1 activation. This could mean that U73122 is not sufficient to block an increase in $\left[\mathrm{Ca}^{2+}\right]_{\mathrm{i}}$ and/or the formation of DAG. Indeed, PLC-independent pathways for $\mathrm{Ca}^{2+}$ influx and DAG formation have been described. ${ }^{7,28,29}$ Alternatively, a third, still-unknown pathway is involved in the regulation of fMLPinduced Rap1 activation.

It is unlikely that fMLP-induced Rap1 activation is mediated by PI-3K, ${ }^{24,30}$ because the PI-3K inhibitors wortmannin and LY294002 also failed to abolish Rap1 activation either.

It was shown previously that Rap1 is present in a complex with cytochrome $b_{558}$ of the NADPH oxidase and cotranslocates with cytochrome $b_{558}$ from the specific granules to the plasma or phagosome membrane after stimulation. ${ }^{10,11}$ Our results show that association of Rap1 with cytochrome $b_{558}$ or an assembled oxidase complex is not necessary for Rap1 activation. This conclusion was based on our observation that Rap1 is normally activated in neutrophils from CGD patients that lack either p91phox or p47phox. Furthermore, $\mathrm{PGE}_{2}$, which was reported to induce Rap1 phosphorylation and dissociation from cytochrome $\mathrm{b}_{558},{ }^{25}$ did not abolish Rap1 activation.

Our finding that Rap1 is activated after stimulation of both receptor associated-tyrosine kinases (GM-CSF) and serpentine 
receptors (fMLP and PAF) indicates that Rap1 functions in a pathway common to both receptor types. Interestingly, only GM-CSF but not fMLP induces phosphorylation of Clb. ${ }^{31}$ This protein has been implicated in the activation of Rap1 through the recruitment of $\mathrm{C} 3 \mathrm{G}$, an exchange factor for Rap1, to $\mathrm{Cbl}$ via the adaptor protein Crk or Crk-L. ${ }^{32,33}$ However, if indeed Cbl mediates Rap1 activation, pathways inducing Rap1 activation after fMLP stimulation would be independent of Cbl phosphorylation.

Although the function of Rap1 is unknown, it has been suggested that Rap1 activity is required for respiratory burst. ${ }^{10,11}$ Our results show that Rap1 activation in vivo is not sufficient to induce a respiratory burst. Perhaps Rap1 activation is only involved in one of the events regulating the multistep process of generating a respiratory burst. Rap1 activity has also been found in human platelets. ${ }^{12}$ Both neutrophils and platelets are highly specialized, and Rap1 is possibly involved in a specific function common to both cell types. The reported association of Rap1 to cytochrome $b_{588}$, in human neutrophils may indicate that Rap1 is involved in the regulation of complex formation. In platelets, a close relative of Rap1, Rap2, has been found in a complex with the major platelet integrin $\alpha \mathrm{II}_{\mathrm{b}} \beta_{3},{ }^{34}$ suggesting a similar role for Rap2 in platelets. Furthermore, in both cell types, Rap1 is at least partly localized on vesicular structures and is translocated to the plasma membrane upon activation. ${ }^{35}$ Interestingly, the Rap homologue in the budding yeast Saccharomyces cerevisiae, Rsr1 (Bud1) is involved in the selection of the site where a new bud will form. ${ }^{36}$ Perhaps Rap1 regulates the formation and/or translocation of protein complexes by specifying the fusion of different cellular compartments, such as the fusion of secretory vesicles with the plasma membrane. It is suggested that Rap1 is involved in regulated insulin secretion. ${ }^{37}$

To decipher the function of Rap1 it will be essential to know which effector protein binds to Rap1GTP. Interestingly, the effector domain of Rap1 is virtually identical to the effector domain of Ras, ${ }^{38-40}$ and it has been shown that Rap1 also binds to Ras effector proteins, including Ral guanine nucleotide exchange factors (RalGEFs) and Raf kinases. ${ }^{41-44}$ In neutrophils and platelets, Rap1 may activate one of the Raf1 kinase signaling cascades, ${ }^{43,44}$ or Rap1 may activate one of the RalGEFs resulting in the activation of the small GTPase $\mathrm{Ral}^{41,45}$ This protein is involved in the activation of phospholipase $\mathrm{D},{ }^{46}$ which, together with members of the Arf family of small GTPases, may control translocation and fusion of granules. ${ }^{47}$

\section{ACKNOWLEDGMENT}

The authors thank Drs B. Burgering and K. Reedquist for support, discussions, and critically reading the manuscript.

\section{REFERENCES}

1. DeLeo FR, Quinn MT: Assembly of the phagocyte NADPH oxidase: Molecular interaction of oxidase proteins. J Leukoc Biol 60:677, 1996

2. Bokoch GM: Regulation of phagocyte function by low molecular weight GTP-binding proteins. Eur J Haematol 51:313, 1993

3. Haslett C, Savill JS, Meagher L: The neutrophil. Curr Opin Immunol 2:10, 1989

4. Sandborg RR, Smolen JE: Early biochemical events in leukocyte activation. Lab Invest 59:300, 1988
5. Sha'afi RI, Molski TF: Activation of the neutrophil. Prog Allergy 42:1, 1988

6. Coffer PJ, Geijsen N, M'Rabet L, Schweizer RC, Maikoe T, Raaijmakers JAM, Lammers JWJ, Koenderman L: Comparison of the roles of mitogen-activated protein kinase kinase and phosphatidylinositol 3-kinase signal transduction in neutrophil effector function. Biochem J 329:121, 1998

7. Bokoch GM: Chemoattractant signaling and leukocyte activation. Blood 86:1649, 1995

8. Quinn MT, Parkos CA, Walker L, Orkin SH, Dinauer MC, Jesaitis AJ: Association of a Ras-related protein with cytochrome b of human neutrophils. Nature 342:198, 1989

9. Abo A, Boyhan A, West I, Thrasher AJ, Segal AW: Reconstitution of neutrophil NADPH oxidase activity in the cell-free system by four components: p67-phox, p47-phox, p21rac1, and cytochrome b-245. J Biol Chem 267:16767, 1992

10. Gabig TG, Crean CD, Mantel PL, Rosli R: Function of wild-type or mutant Rac2 and Rap1a GTPases in differentiated HL60 cell NADPH oxidase activation. Blood 85:804, 1995

11. Maly FE, Quilliam LA, Dorseuil O, Der CJ, Bokoch GM: Activated or dominant inhibitory mutants of Rap1A decrease the oxidative burst of Epstein-Barr virus-transformed human B lymphocytes. J Biol Chem 269:18743, 1994

12. Franke B, Akkerman J-WN, Bos JL: Rapid Ca2+-mediated activation of Rap1 in human platelets. EMBO J 16:252, 1997

13. Koenderman L, Kok PT, Hamelink ML, Verhoeven AJ, Bruijnzeel PL: An improved method for the isolation of eosinophilic granulocytes from peripheral blood of normal individuals. J Leukoc Biol 44:79, 1988

14. Segal AW, Coade SB: Kinetics of oxygen consumption by phagocytosing human neutrophils. Biochem Biophys Res Commun 84:611, 1978

15. Dewald B, Baggiolini M: Activation of NADPH oxidase in human neutrophils. Synergism between fMLP and the neutrophil products PAF and LTB4. Biochem Biophys Res Commun 128:297, 1985

16. Ingraham LM, Coates TD, Allen JM, Higgins CP, Baehner RL, Boxer LA: Metabolic, membrane, and functional responses of human polymorphonuclear leukocytes to platelet-activating factor. Blood 59: 1259,1982

17. Weisbart RH, Kwan L, Golde DW, Gasson JC: Human GM-CSF primes neutrophils for enhanced oxidative metabolism in response to the major physiological chemoattractants. Blood 69:18, 1987

18. Koenderman L, Yazdanbakhsh M, Roos D, Verhoeven AJ: Dual mechanisms in priming of the chemoattractant-induced respiratory burst in human granulocytes. A $\mathrm{Ca}^{2+}$-dependent and a $\mathrm{Ca}^{2+}$ independent route. J Immunol 142:623, 1989

19. Weening RS, Roos D, Loos JA: Oxygen consumption of phagocytizing cells in human leukocyte and granulocyte preparations: A comparative study. J Lab Clin Med 83:570, 1974

20. Edwards SW: Cell signalling by integrins and immunoglobulin receptors in primed neutrophils. Trends Biochem Sci 20:362, 1995

21. Thelen M, Wirthmueller U: Phospholipases and protein kinases during phagocyte activation. Curr Opin Immunol 6:106, 1994

22. Didichenko SA, Tilton B, Hemmings BA, Ballmer-Hofer K, Thelen M: Constitutive activation of protein kinase B and phosphorylation of p47phox by a membrane-targeted phosphoinositide 3-kinase. Curr Biol 6:1271, 1996

23. Tilton B, Andjelkovic M, Didichenko SA, Hemmings BA, Thelen M: G-protein-coupled receptors and Fcgamma-receptors mediate activation of Akt/protein kinase B in human phagocytes. J Biol Chem 272:28096, 1997

24. Ding J, Vlahos CJ, Liu R, Brown RF, Badwey JA: Antagonists of phosphatidylinositol 3-kinase block activation of several novel protein kinases in neutrophils. J Biol Chem 270:11684, 1995 
25. Bokoch GM, Quilliam LA, Bohl BP, Jesaitis AJ, Quinn MT: Inhibition of Rap1A binding to cytochrome b558 of NADPH oxidase by phosphorylation of Rap1A. Science 254:1794, 1991

26. Segal AW: The NADPH oxidase and chronic granulomatous disease. Mol Med Today 2:129, 1996

27. Reedquist KA, Bos JL: Costimulation through CD28 suppresses $\mathrm{T}$ cell receptor-dependent activation of the Ras-like small GTPase Rap1 in human T lymphocytes. J Biol Chem 273:4944, 1998

28. Thelen M, Dewald B, Baggiolini M: Neutrophil signal transduction and activation of the respiratory burst. Physiol Rev 73:797, 1993

29. Tou J, Jeter JR Jr, Dola CP, Venkatesh S: Accumulation of phosphatidic acid mass and increased de novo synthesis of glycerolipids in platelet-activating-factor-activated human neutrophils. Biochem J 280:625, 1991

30. Thelen M, Wymann MP, Langen H: Wortmannin binds specifically to 1-phosphatidylinositol 3-kinase while inhibiting guanine nucleotide-binding protein-coupled receptor signaling in neutrophil leukocytes. Proc Natl Acad Sci USA 91:4960, 1994

31. Naccache PH, Gilbert C, Barabe F, Al-Shami A, Mahana W, Bourgoin SG: Agonist-specific tyrosine phosphorylation of $\mathrm{Cbl}$ in human neutrophils. J Leukoc Biol 62:901, 1997

32. Reedquist KA, Fukazawa T, Panchamoorthy G, Langdon WY, Shoelson SE, Druker BJ, Band H: Stimulation through the T cell receptor induces $\mathrm{Cbl}$ association with $\mathrm{Crk}$ proteins and the guanine nucleotide exchange protein C3G. J Biol Chem 271:8435, 1996

33. Smit L, van der Horst G, Borst J: Sos, Vav, and C3G participate in $\mathrm{B}$ cell receptor-induced signaling pathways and differentially associate with Shc-Grb2, Crk, and Crk-L adaptors. J Biol Chem 271:8564, 1996

34. Torti M, Ramaschi G, Sinigaglia F, Lapetina EG, Balduini C: Glycoprotein IIb-IIIa and the translocation of Rap2B to the platelet cytoskeleton. Proc Natl Acad Sci USA 91:4239, 1994

35. Berger G, Quarck R, Tenza D, Levy-Toledano S, de Gunzburg J, Cramer EM: Ultrastructural localization of the small GTP-binding protein Rap1 in human platelets and megakaryocytes. $\mathrm{Br} \mathrm{J}$ Haematol 88:372, 1994

36. Chant J, Herskowitz I: Genetic control of bud site selection in yeast by a set of gene products that constitute a morphogenetic pathway. Cell 65:1203, 1991

37. Leiser M, Efrat S, Fleischer N: Evidence that Rap1 carboxylmethylation is involved in regulated insulin secretion. Endocrinology 136:2521, 1995

38. Kawata M, Matsui Y, Kondo J, Hishida T, Teranishi Y, Takai Y: A novel small molecular weight GTP-binding protein with the same putative effector domain as the Ras proteins in bovine brain membranes: Purification, determination of the primary structure and characterisation. J Biol Chem 263:18965, 1988

39. Pizon V, Chardin P, Lerosey I, Olofsson B, Tavitian A: Human cDNAs Rap1 and Rap2 homologous to the Drosophila gene Dras3 encode proteins closely related to ras in the 'effector' region. Oncogene 3:201, 1988

40. Kitayama H, Sugimoto Y, Matsuzaki T, Ikawa Y, Noda M: A ras-related gene with transformation suppressor activity. Cell 56:77, 1989

41. Herrmann C, Horn G, Spaargaren M, Wittinghofer A: Differential interaction of the ras family GTP-binding proteins H-Ras, Rap1A, and R-Ras with the putative effector molecules Raf kinase and Ral-guanine nucleotide exchange factor. J Biol Chem 271:6794, 1996

42. Bos JL, Franke B, M'Rabet L, Reedquist K, Zwartkruis F: In search of a function for the Ras-like GTPase Rap1. FEBS Lett 410:59, 1997

43. Vossler MR, Yao H, York RD, Pan M-G, Rim SM, Stork PJS: cAMP activates MAP kinase and Elk 1 through a B-raf- and Rap1 dependent pathway. Cell 89:74, 1997

44. Wolthuis RMF, Zwartkruis F, Moen TC, Bos JL: Ras-dependent activation of the small GTPase Ral. Curr Biol 8:471, 1998

45. Wolthuis RM, Franke B, van Triest M, Bauer B, Cool RH, Camonis JH, Akkerman JW, Bos JL: Activation of the small GTPase Ral in platelets. Mol Cell Biol 18:2486, 1998

46. Jiang H, Luo JQ, Urano T, Frankel P, Lu Z, Foster DA, Feig LA: Involvement of Ral GTPase in v-Src-induced phospholipase D activation. Nature 378:409, 1995

47. Cockcroft S, Thomas GM, Fensome A, Geny B, Cunningham E, Gout I, Hiles I, Totty NF, Truong O, Hsuan JJ: Phospholipase D: A downstream effector of ARF in granulocytes. Science 263:523, 1994 